\title{
Is coronary artery tortuosity a precursor of atherosclerosis and/or left ventricular diastolic dysfunction?
}

\author{
Zainab Atiyah Dakhili
}

To the Editor,

RE: "Coronary tortuosity relation with carotid intimamedia thickness, coronary artery disease risk factors, and diastolic dysfunction: is it a marker of early atherosclerosis?", March 31, 2021.

We read with interest the thoughtful paper by Ahmed Alamragy et al. [1] that highlighted the association of coronary artery tortuosity (CAT) with increased carotid intima-media thickness (CIMT), hypertension, hyperlipidemia, left ventricular diastolic dysfunction (DD), and coronary artery atherosclerosis, so this study contributes well to the existing literature especially if we consider how common is this socalled benign coronary phenotype and how limited data are there regarding its significance. Nevertheless, there are certain issues that we would like to raise regarding this study.

This study referred only to tortuous main coronary arteries without mentioning if sizable side branches' tortuosity was excluded or not from the control group; side branch tortuosity has been reported as negative predictor of atherosclerosis [2], and we think it might be important to at least mention if they were considered especially if they were large side branches that irrigate large area of myocardium.

The researchers did well with choosing age- and gender-matched control patients because of the debate of the impact of these factors on CAT; however, one of the main findings of this study is the diastolic dysfunction that was observed more in the CAT group, yet the researchers did not exclude other causes of DD from the CAT group like hypertension, obesity, and thyroid diseases [3, 4], and this might remarkably affect the results especially if we consider that the study showed that $86.7 \%$ of the CAT group vs. $30 \%$ of the control group were hypertensive which might explain the higher prevalence of DD in the CAT group. Despite that the researchers excluded uncontrolled hypertension (which the study did not define), still hypertension is well recognized cause of DD that might impact the results. This is more crucial if we consider that no multiple regression analysis was done to assess the predictors of DD in this study which could better waive the impact of the case selection issue.

The main question of this study was to determine the predictors for CAT, yet the title did not clearly reflect this objective; however, the question was clearly answered despite the small study population.

It is also noteworthy to mention that coronary artery tortuosity can be part of systemic arterial tortuosity [5], so carotid artery tortuosity can be associated with CAT, which might explain the increased CIMT here rather than the direct association of this CIMT increase with CAT, as the atherosclerotic changes in tortuous arteries are reported to be due to local shear stress forces, so such possibility needs to be evaluated in future studies especially with the conflicting existing literature.

Interestingly, assessment of coronary artery calcium burden by CT coronary angiography is a surrogate for coronary atherosclerosis, and its relation with CAT is also a matter of debate $[6,7]$, so it can be further investigated in future studies.

Despite the raised issues, we believe that this study can open the door for future researchers to further explore the significance of coronary artery tortuosity. 


\section{Abbreviations}

CAT: Coronary artery tortuosity; CIMT: Carotid intima-media thickness;

DD: Left ventricular diastolic dysfunction

\section{Acknowledgements}

Not applicable.

\section{Author's contributions}

ZD conceptualize the letter, drafted, and revised the letter. The author read and approved the final manuscript.

\section{Funding}

Not applicable.

\section{Availability of data and materials} Not applicable.

\section{Declarations}

Ethics approval and consent to participate

Not applicable

\section{Consent for publication}

Not applicable.

\section{Competing interests}

The author declares no competing interests.

Received: 13 April 2021 Accepted: 16 July 2021

Published online: 28 July 2021

\section{References}

1. Elamragy A, Yakoub S, AbdelGhany M, Ammar W (2021) Coronary tortuosity relation with carotid intima-media thickness, coronary artery disease risk factors, and diastolic dysfunction: is it a marker of early atherosclerosis? The Egyptian Heart Journal 73(1):1-9

2. Kurihara K, Fujimori Y, Yamanaka Y, Baba T, Hashimoto S, Takeuchi W, Wakabayashi T, Yokota D, Imai T (2020 Mar 24) Tortuous coronary segments with bending and stretching motion: a possible preventive factor against coronary atherosclerosis. J Am Coll Cardiol 75(11_Supplement_1):89

3. Slama M, Susic D, Varagic J, Frohlich ED (2002 Jul 1) Diastolic dysfunction in hypertension. Curr Opin Cardiol 17(4):368-373. https://doi.org/10.1097/ 00001573-200207000-00008

4. Neves JS, Vale C, von Hafe M, Borges-Canha M, Leite AR, Almeida-Coelho J, Lourenço A, Falcão-Pires I, Carvalho D, Leite-Moreira A (2020) Thyroid hormones and modulation of diastolic function: a promising target for heart failure with preserved ejection fraction. Therapeutic Advances in Endocrinology and Metabolism 11:2042018820958331

5. Davutoglu V, Dogan A, Okumus S, Demir T, Tatar G, Gurler B, Ercan S, Sari I, Alici H, Altunbas G (2013 Jan 1) Coronary artery tortuosity: comparison with retinal arteries and carotid intima-media thickness. Kardiol Pol 71(11):11211128. https://doi.org/10.5603/KP.a2013.0292

6. Kahe F, Sharfaei S, Pitliya A, Jafarizade M, Seifirad S, Habibi S, Chi G (2020 Mar 1) Coronary artery tortuosity: a narrative review. Coron Artery Dis $31(2)$ : 187-192. https://doi.org/10.1097/MCA.0000000000000769

7. Dakhil ZA, Farhan HA Clinical landscape, calcium burden and angiographic profile in coronary artery tortuosity: how does the gender contribute? Catheter Cardiovasc Interv 99(S1):S48-S49

\section{Publisher's Note}

Springer Nature remains neutral with regard to jurisdictional claims in published maps and institutional affiliations.

\section{Submit your manuscript to a SpringerOpen ${ }^{\circ}$ journal and benefit from:}

- Convenient online submission

- Rigorous peer review

- Open access: articles freely available online

- High visibility within the field

- Retaining the copyright to your article

Submit your next manuscript at $\boldsymbol{\nabla}$ springeropen.com 